\title{
Effects of diet form and feeder adjustment on growth performance of nursery and finishing pigs ${ }^{1}$
}

\author{
J. E. Nemechek, * M. D. Tokach, * S. S. Dritz, $†$ E. D. Fruge, \\ E. L. Hansen, R. D. Goodband,*2 J. M. DeRouchey,* and J. C. Woodworth*
}

*Department of Animal Sciences and Industry, College of Agriculture,

Kansas State University, Manhattan 66506-0201; †Department of Diagnostic Medicine/Pathobiology, College of Veterinary Medicine, Kansas State University, Manhattan 66506-0201; and \$Hubbard Feeds, Mankato, MN 56002

\begin{abstract}
Three experiments were conducted to determine the effects of feeder adjustment and diet form on growth performance of nursery (Exp. 1 and 2) and finishing (Exp. 3) pigs. Treatments were arranged as a $2 \times 3$ factorial with the main effects of feeder adjustment and diet form. The 2 feeder adjustments were a narrow and wide feeder adjustment (minimum gap opening of 1.27 and $2.54 \mathrm{~cm}$, respectively). The 3 diet forms were meal, poor-quality pellets $(70 \%$ pellets and 30\% fines for Exp. 1 and 2 and 50\% pellets and $50 \%$ fines for Exp. 3), and screened pellets with minimal fines (3 to 10\%). In Exp. 1, 210 pigs (initially 11.9 $\mathrm{kg} \mathrm{BW})$ were used in a 21-d trial with 7 pigs per pen and 5 pens per treatment. No feeder adjustment $\times$ diet form interactions were observed. There were no differences in ADG, ADFI, or G:F due to feeder adjustment. Pigs fed the meal diet had increased $(P<0.05)$ ADG and ADFI compared with pigs fed the poor-quality or screened pellets. Pigs fed meal or poor-quality pellets had decreased $(P<0.05) \mathrm{G}: F$ compared with pigs fed screened pellets. In Exp. 2, 1,005 nursery pigs (initially $14.1 \mathrm{~kg} \mathrm{BW}$ ) were used in a 28 -d trial with 26 to 28 pigs per pen and 6 pens per treatment. Pigs fed from the narrow feeder adjustment had decreased $(P<$
\end{abstract}

0.05) ADG and ADFI compared with pigs fed from the wide adjustment with no differences in G:F. Pigs fed the meal diet had decreased $(P<0.05)$ ADG compared with pigs fed poor-quality or screened pellets. Pigs fed meal or poor-quality pellets had decreased $(P<0.05)$ $\mathrm{G}: \mathrm{F}$ compared with pigs fed screened pellets. In Exp. 3, 246 pigs (initially $56.8 \mathrm{~kg} \mathrm{BW}$ ) were used in a 69-d trial with 5 pens per treatment and 6 or 7 pigs per pen. Overall, ADFI decreased $(P<0.05)$ and G:F increased $(P<0.05)$ for pigs fed from the narrow adjusted feeders compared with the wide adjustment with no differences in ADG. Overall, pigs fed meal diets tended to have decreased $(P<0.10)$ ADG and had decreased $(P<0.05) \mathrm{G}:$ F compared with pigs fed screened pellets; ADG and G:F in those fed poor-quality pellets were intermediate. Feeding meal or poor-quality pellets increased $(P<0.05)$ ADFI compared with pigs fed screened pellets. In conclusion, feeding nursery pigs from a wide feeder gap may increase ADG and ADFI with no negative effects on G:F. For finishing pigs, reducing feeder gap reduced feed disappearance and improved G:F. In all experiments, the greatest G:F improvements from pelleting were observed when the percentage of fines was minimized.

Key words: feeder adjustment, growth, pellet quality, pig doi:10.2527/jas2015-9028

\section{INTRODUCTION}

The importance of minimizing feed wastage has increased interest in feeder adjustment and the ideal feeder pan coverage. In finishing pigs, Myers et al. (2012) re-

\footnotetext{
${ }^{1}$ Contribution number 15-275-J from the Kansas Agric. Exp. Sta., Manhattan, KS 66506-0210.

${ }^{2}$ Corresponding author: Goodband@ksu.edu

Received February 19, 2015.

Accepted June 12, 2015.
} ported that wide feeder gap adjustments decreased G:F, a result that was attributed to increased feed wastage. They recommended decreased percentage pan coverage as BW range increased for optimal growth performance. 
Despite improvements in G:F with narrow feeder adjustments, providing too little pan coverage restricts access to feed and reduces the weight gain of pigs (Smith et al., 2004; Duttlinger et al., 2009). Feeder gap management research has been conducted using meal or crumbled diets and has not provided guidance for feeding pelleted diets.

The growth performance benefits of feeding pelleted diets to swine have been known for decades (Baird, 1973). Wondra et al. (1995) reported a 4 to $6 \%$ increase in $\mathrm{ADG}$ and 7\% improvement in G:F when pelleted diets were fed to finishing pigs compared with meal diets. The quality of the pellets has been shown to be an important aspect of the overall response. Stark et al. (1993) observed that the feed efficiency benefit from pellets is related to the percentages of fines in the diets. Compared with meal diets, feeding screened pellets with minimal fines to nursery pigs provided an $11 \% \mathrm{im}-$ provement in G:F, which was greater than the $8 \%$ improvement when feeding pellets with $25 \%$ fines. They also observed that finishing pig feed efficiency linearly worsened as percentage fines increased in the diet.

Although feeder gap adjustment and pellet quality have been researched independently, no research has been conducted to investigate their relationship. We hypothesized that diets containing a high level of fines may require a narrower feeder gap adjustment to decrease wastage. Therefore, 3 experiments were conducted to determine the effects of feeder adjustment and diet form (meal vs. poor-quality or high-quality pellets) on growth performance of nursery and finishing pigs.

\section{MATERIALS AND METHODS}

All experimental procedures and animal care were approved by the Kansas State University Institutional Animal Care and Use Committee (Manhattan, KS).

\section{Animals and Housing}

In Exp. 1, 210 nursery pigs $(327 \times 1,050$; PIC, Hendersonville, $\mathrm{TN}$; initially $11.9 \mathrm{~kg} \mathrm{BW}$ ) were used in a 21 -d trial with 7 pigs per pen and 5 pens per treatment. The experiment was conducted in the nursery facility at the Kansas State University Swine Teaching and Research Center in Manhattan, KS. All pens (1.52 by 1.83 $\mathrm{m})$ were equipped with a nipple waterer, wire-mesh floors, and a 3-hole, dry self-feeder (Smidley Mfg., Inc., Britt, IA). Each feeder hole was $13.6 \mathrm{~cm}$ in length with a 14.0-cm horizontal depth (measured from the front lip to the back of the pan) and a $6.4-\mathrm{cm}$ vertical depth (measured from the bottom of the pan to the height of the feeder lip). Diets were manufactured and delivered in $22.7-\mathrm{kg}$ bags. Feed was weighed and hand-added to each pen as needed to provide ad libitum access.
In Exp. 2, a total of 1,005 nursery pigs (TR4 $\times$ Fast Genetics [Saskatoon, SK] $\times$ PIC L02; initially $14.1 \mathrm{~kg}$ BW) were used in a 28 -d trial, with 26 to 28 pigs per pen and 6 pens per treatment. The trial was conducted at New Fashion Pork's Nursery Research Facility in Buffalo Center, IA. All pens (1.83 by $3.96 \mathrm{~m})$ contained a nipple waterer and a 5-hole dry self-feeder. Each feeder hole was $15.2 \mathrm{~cm}$ in length with a $12.7-\mathrm{cm}$ horizontal depth (measured from the front lip to the back of the pan) and 7.6-cm vertical depth (measured from the bottom of the pan to the height of the feeder lip). Diets were delivered in bulk, and feed was weighed and hand-added to each pen as needed to provide ad libitum access.

In Exp. 3, 252 finishing pigs $(327 \times 1,050$; PIC; 56.8 $\mathrm{kg} \mathrm{BW}$ ) were used in a 69 -d trial. There were 5 pens per treatment with 7 pigs and 1 replicate with 6 pigs per pen. The trial was conducted in the finishing pig facility at the Kansas State University Swine Teaching and Research Center in Manhattan, KS. The facility was a totally enclosed, environmentally regulated, mechanically ventilated barn containing 36 pens ( 2.44 by 3.05 $\mathrm{m})$. The pens had adjustable gates facing the alleyway and allowed $0.93 \mathrm{~m}^{2} / \mathrm{pig}$. Each pen was equipped with a cup waterer and a single-sided, dry self-feeder (Farmweld, Teutopolis, IL) with 2 eating spaces located in the fence line. Each feeder hole was $35.6 \mathrm{~cm}$ in length with a $27.9-\mathrm{cm}$ horizontal depth (measured from the front lip to the back of the pan) and a $12.7-\mathrm{cm}$ vertical depth (measured from the bottom of the pan to the height of the feeder lip). Pens were located over a completely slatted concrete floor with a $1.20-\mathrm{m}$ pit underneath for manure storage. Similar to Exp. 2, diets were delivered in bulk and fed through bulk bins using a computerized feeding system (FeedPro; Feedlogic Corp., Willmar, $\mathrm{MN}$ ) that delivered and recorded diets as specified.

All pigs were provided with ad libitum access to feed and water. Pigs and feeders were weighed weekly for Exp. 1 and 2 and approximately every 2 wk for Exp. 3 to calculate ADG, ADFI, and G:F.

\section{Treatments and Diet Manufacturing}

Similar treatments and procedures were used in all experiments. Pens were randomly allotted to 1 of 6 experimental treatments in a completely randomized design. Treatments were arranged in a $2 \times 3$ factorial with the main effects of feeder adjustment and diet form. The 2 feeder adjustment treatments consisted of a narrow adjustment (minimum gap opening of 1.27 $\mathrm{cm}$ ) and a wide adjustment (minimum gap opening of $2.54 \mathrm{~cm}$ ). The feeders were adjusted to the minimum gap setting, but the agitation plate (feeder gate) could be moved upward to a maximum gap opening of 1.91 or $3.18 \mathrm{~cm}$, respectively. These settings remained 
fixed throughout each experiment. The 3 diet form treatments consisted of meal, poor-quality pellets, and screened pellets with minimal fines (3 to 10\%). In the nursery trials (Exp. 1 and 2), the poor-quality pellets consisted of approximately $70 \%$ pellets and $30 \%$ fines. For the finishing trial (Exp. 3), the poor-quality pellets consisted of approximately $50 \%$ pellets and $50 \%$ fines.

For all 3 experiments, the exact same ingredients and particle size were used for all diets with a target particle size for the corn of 500 to $600 \mu \mathrm{m}$. Thus, particle size was the same for meal and pelleted diets within each experiment. Diets for Exp. 1 were prepared and pelleted at the K-State Grain Sciences and Industry Feed Mill in Manhattan, KS. Pelleted diets were manufactured using a 30 hp California Pellet Mill (Crawfordsville, IN) 1000 series Master HD model pellet mill. The pellet mill was equipped with a $31.75-\mathrm{mm}$-thick die with $3.97-\mathrm{mm}$ hole diameters. Before pelleting, feed was conditioned with steam at approximately $79.5^{\circ} \mathrm{C}$. Diets for Exp. 2 and 3 were manufactured at Hubbard Feeds in Mankato, MN, and Atlantic, IA, respectively. In accordance with the capabilities of each feed mill, the desired level of fines in the poor-quality pellets were created by 2 different methods. For Exp. 1, pellets were manufactured and screened to remove and collect fines. After the screened pelleted diet was bagged, the fines were added back to the remaining pellets. The mixture of pellets and fines was then added to the mixer, and additional fines were created in the mixer by mechanical breakdown. For Exp. 2 and 3, the pellets were passed through a roller mill, rather than the mixer, to create the additional fines. To ensure the desired level of fines was achieved, feed samples were taken at the feeder during each experiment. The percentages of fines (ASAE, 1987) were measured for all pelleted diets, with fines characterized as material that would pass through a number 6 sieve $(3,360-\mu \mathrm{m}$ openings). All pellet quality measurements were analyzed at the $\mathrm{O}$. H. Kruse Feed Technology Innovation Center (Manhattan, KS).

Dietary ingredients were similar among all experiments, and diets were formulated to contain identical ingredient compositions within each experiment (NRC, 2012; Table 1). In Exp. 1 and 2, diets were fed in 1 phase and were corn-soybean meal-based with $20 \%$ distiller's dried grains with solubles (DDGS). Diets for Exp. 3 were corn-soybean meal-based and fed in 3 phases with decreasing nutrient concentrations in each phase. Phases 1 and 2 contained 20\% DDGS, and phase 3 contained 10\% DDGS.

\section{Feeder Pan Coverage Scoring}

For Exp. 1 and 2, a digital photo of each feeder pan was taken on the last day (d 21 and 28, respectively) of each trial before weighing the pigs and feeders. For
Exp. 3, photos were taken at the conclusion of phases 1, 2, and 3 (d 22, 48, and 69, respectively). Each feeder pan picture was then scored by 5 evaluators for percentage of pan coverage, and all scores were used to calculate the mean pan coverage for each feeder.

\section{Statistical Analysis}

Experimental data for both trials were analyzed using ANOVA as a $2 \times 3$ factorial using the MIXED procedure of SAS (SAS Inst. Inc., Cary, NC). Pen was the experimental unit for all data analysis. Data analysis for all trials included the main effects of 2 feeder adjustments, 3 diet forms, and their interaction as fixed effects. For the pan scores and growth data in Exp. 3, a repeated ANOVA by phase was performed. When a significant difference was found between diet forms, differences between treatments were determined using the PDIFF statement in SAS. Significant differences were declared at $P<0.05$ and trends at $P<0.10$.

\section{RESULTS}

\section{Experiment 1}

Determination of the percentage of fines revealed that the poor-quality pellets contained $67 \%$ pellets and $33 \%$ fines whereas the screened pelleted diet contained $97 \%$ pellets and $3 \%$ fines (Table 2 ).

No feeder gap adjustment $\times$ diet form interactions were observed for pig performance or pan scores and, thus, main effects are presented (Table 3 ). Overall (d 0 to 21), no differences were observed in ADG, ADFI, or G:F between pigs fed from feeders with the different adjustment settings. Feeders with the wider feeder gap setting had increased pan coverage $(P<0.001)$. Pigs fed the meal diet had increased $(P<0.05)$ ADG and ADFI compared with pigs fed the poor-quality or screened pelleted diets. Pigs fed screened pellets had improved $(P<0.05)$ $\mathrm{G}: \mathrm{F}$ compared with pigs fed meal or poor-quality pellets.

\section{Experiment 2}

The poor-quality pellets contained $63 \%$ pellets and $37 \%$ fines whereas the screened pelleted diet contained $95 \%$ pellets and $5 \%$ fines.

No feeder gap adjustment $\times$ diet form interactions were observed for pig performance or pan coverage scores (Table 4). Overall (d 0 to 28), pigs fed from feeders with the wide feeder adjustment had increased $(P<0.05)$ ADG and ADFI, but feed efficiency did not differ among pigs fed from the different feeder gap adjustments. Feeders with the wider feeder gap setting had increased pan coverage $(P<0.001)$. Pigs fed 
Table 1. Diet composition (as-fed basis)

\begin{tabular}{|c|c|c|c|c|c|}
\hline \multirow[b]{2}{*}{ Item } & \multirow[b]{2}{*}{ Exp. 1} & \multirow[b]{2}{*}{ Exp. 2} & \multicolumn{3}{|c|}{ Exp. 3} \\
\hline & & & Phase 1 & Phase 2 & Phase 3 \\
\hline \multicolumn{6}{|l|}{ Ingredient, \% } \\
\hline Corn & 42.78 & 48.30 & 59.75 & 63.08 & 76.04 \\
\hline Soybean meal, $46.5 \% \mathrm{CP}$ & 30.95 & 27.10 & 17.05 & 14.00 & 11.65 \\
\hline Dried distillers grains with solubles & 20.00 & 20.00 & 20.00 & 20.00 & 10.00 \\
\hline Soybean oil & 3.00 & - & - & - & - \\
\hline Choice white grease & - & 1.30 & 1.35 & 1.15 & 0.75 \\
\hline Monocalcium P, 21\% P & 0.60 & 0.60 & - & - & - \\
\hline Limestone & 1.25 & 0.87 & 1.01 & 0.99 & 0.85 \\
\hline Salt & 0.35 & 0.50 & 0.35 & 0.35 & 0.35 \\
\hline Trace mineral premix ${ }^{1}$ & 0.150 & 0.075 & 0.100 & 0.100 & 0.085 \\
\hline Vitamin premix ${ }^{2}$ & 0.250 & 0.030 & 0.030 & 0.030 & 0.030 \\
\hline Copper sulfate & - & 0.066 & - & - & - \\
\hline Selenium, $0.2 \% \mathrm{Se}$ & - & - & 0.015 & 0.015 & 0.015 \\
\hline L-Lys $\times \mathrm{HCl}$ & 0.375 & 0.402 & 0.300 & 0.250 & 0.200 \\
\hline DL-Met & 0.060 & - & - & - & - \\
\hline Methionine hydroxy analog & - & 0.120 & - & - & - \\
\hline L-Thr & 0.070 & 0.092 & - & - & - \\
\hline Phytase $^{3}$ & 0.165 & 0.040 & 0.041 & 0.041 & 0.041 \\
\hline Antibiotic $^{4}$ & - & 0.400 & - & - & - \\
\hline Mold inhibitor ${ }^{5}$ & - & 0.100 & - & - & - \\
\hline Total & 100.0 & 100.0 & 100.0 & 100.0 & 100.0 \\
\hline \multicolumn{6}{|l|}{ Calculated analysis } \\
\hline \multicolumn{6}{|l|}{ Standardized ileal digestible (SID) AA, \% } \\
\hline Lys & 1.30 & 1.20 & 0.90 & 0.79 & 0.67 \\
\hline Ile:Lys & 64 & 62 & 68 & 71 & 71 \\
\hline Met:Lys & 33 & 34 & 32 & 35 & 35 \\
\hline Met + Cys:Lys & 58 & 58 & 62 & 68 & 69 \\
\hline Thr:Lys & 62 & 62 & 61 & 64 & 64 \\
\hline Trp:Lys & 17.6 & 18 & 18 & 19 & 19 \\
\hline Val:Lys & 73 & 73 & 83 & 88 & 88 \\
\hline Total Lys, $\%$ & 1.50 & 1.38 & 1.04 & 0.92 & 0.77 \\
\hline ME, $\mathrm{kcal} / \mathrm{kg}$ & 3,468 & 3,309 & 3,351 & 3,352 & 3,358 \\
\hline $\mathrm{NE}, \mathrm{kcal} / \mathrm{kg}$ & 2,306 & 2,345 & 2,477 & 2,053 & 2,556 \\
\hline $\mathrm{CP}, \%$ & 23.9 & 21.9 & 17.7 & 16.5 & 13.7 \\
\hline $\mathrm{Ca}, \%$ & 0.71 & 0.68 & 0.48 & 0.47 & 0.40 \\
\hline $\mathrm{P}, \%$ & 0.60 & 0.59 & 0.42 & 0.40 & 0.35 \\
\hline Available P, \% & 0.43 & 0.41 & 0.28 & 0.27 & 0.22 \\
\hline
\end{tabular}

${ }^{1}$ For Exp. 1, provided per kilogram of premix: $26.5 \mathrm{~g} \mathrm{Mn}$ from manganese oxide, $110 \mathrm{~g}$ Fe from iron sulfate, $110 \mathrm{~g} \mathrm{Zn}$ from zinc sulfate, $11 \mathrm{~g}$ Cu from copper sulfate, $198 \mathrm{mg}$ I from calcium iodate, and $198 \mathrm{mg}$ Se from sodium selenite. For Exp. 2 and 3, provided per kilogram of premix: $53.3 \mathrm{~g}$ Mn from manganese sulfate and manganous oxide, $134 \mathrm{~g}$ Fe from iron sulfate, $160 \mathrm{~g} \mathrm{Zn}$ from zinc sulfate, $13.3 \mathrm{~g} \mathrm{Cu}$ from copper sulfate, and 1,370 mg I from calcium iodate.

${ }^{2}$ For Exp. 1, provided per kilogram of premix: 4,409,200 IU vitamin A; 551,150 IU vitamin $\mathrm{D}_{3}$; 17,637 IU vitamin E; 1,764 mg vitamin K; 3,307 mg riboflavin; 11,023 mg pantothenic acid; 19,841 mg niacin; and $15.4 \mathrm{mg}$ vitamin $\mathrm{B}_{12}$. For Exp. 2 and 3, provided per kilogram of premix: 22,046,244 IU vitamin $\mathrm{A}$; 3,968,324 IU vitamin $\mathrm{D}_{3}$; 97,003 IU vitamin $\mathrm{E}$; 10,288 $\mathrm{mg}$ vitamin $\mathrm{K}$; 13,228 $\mathrm{mg}$ riboflavin; 61,729 mg pantothenic acid; 79,366 mg niacin; and $88 \mathrm{mg}$ vitamin $\mathrm{B}_{12}$.

${ }^{3}$ For Exp. 1, Phyzyme 600 (Danisco Animal Nutrition, St. Louis, MO) provided 992 phytase units (FTU)/kg, with a release of $0.13 \%$ available P. For Exp. 2 and 3, Natuphos 2500 (BASF Corporation, Florham Park, NJ), provided 1,000 FTU/kg, with a release of $0.12 \%$ available P.

${ }^{4}$ Chlortetracycline (CTC-50).

${ }^{5}$ Propionic acid-based mold inhibitor (AMMO Kurb; Kemin Industries Inc., Des Moines, IA).

screened pellets or poor-quality pellets had increased $(P<0.05)$ ADG compared with pigs fed the meal diet. No difference in ADFI was observed among pigs fed different diet forms. Similar to Exp. 1, pigs fed screened pellets had improved $(P<0.05) \mathrm{G}: \mathrm{F}$ compared with pigs fed meal or poor-quality pellets.

\section{Experiment 3}

In phase 1 (d 0 to 22 ), the poor-quality pellets that were intended to contain 50\% pellets and 50\% fines actually contained $56 \%$ pellets and $44 \%$ fines. The screened pelleted diet was $92 \%$ pellets and $8 \%$ fines. 
Table 2. Percentage fines of pelleted diets ${ }^{1}$

\begin{tabular}{lcc}
\hline \hline Item & Poor-quality pellet & Screened pellet \\
\hline Percentage fines ${ }^{2}$ & & \\
Exp. 1 & 33 & 3 \\
Exp. 2 & 37 & 5 \\
Exp. 3 & & \\
Phase 1 & 44 & 8 \\
Phase 2 & 52 & 8 \\
Phase 3 & 55 & 10 \\
\hline
\end{tabular}

${ }^{1}$ Feed samples were taken at the feeder for all trials. For Exp. 1 and 2, samples were pooled throughout the entire trial. For Exp. 3, samples were taken and pooled within each phase. All samples were run in duplicate for percentage fines determination.

${ }^{2}$ Fines were characterized as material that would pass through a number 6 sieve $(3,360-\mu \mathrm{m}$ openings $)$.

No feeder adjustment $\times$ diet form interactions were observed during any of the dietary phases or for the overall study (Table 5). A feeder adjustment $\times$ diet form $\times$ phase interaction was not observed for pan coverage score. However, feeder adjustment $\times$ phase and diet form $\times$ phase interactions $(P<0.05)$ were observed.

During phase $1, \mathrm{ADG}$ did not differ among pigs fed from feeders with the different adjustment settings. Pigs fed from feeders with the wide adjustment tended to have increased $(P<0.10)$ ADFI, which resulted in poorer $(P$ $<0.05) \mathrm{G}: \mathrm{F}$ than that in pigs fed from feeders with the narrow adjustment. Feeders with the wider feeder gap setting had increased pan coverage $(P<0.001)$.

For diet form, ADG did not differ among treatments. Pigs fed the meal diet had increased $(P<0.05)$ ADFI compared with pigs fed the poor-quality or screened pellets. Diet form decreased G:F during phase 1, with pigs fed the meal diet having poorer $(P<0.05) \mathrm{G}: \mathrm{F}$ than pigs fed screened pellets; G:F in those fed poor-quality pellets was intermediate. Feeders with screened pellets had lower $(P<0.05)$ pan coverage compared to feeders with unscreened pellets but higher $(P<0.05)$ coverage than feeders with meal diets.
During phase 2 (d 22 to 48), the poor-quality pelleted diet contained $48 \%$ pellets and $52 \%$ fines, whereas the screened pelleted diet contained $92 \%$ pellets and $8 \%$ fines. Average daily gain did not differ among pigs fed from feeders with the different adjustment settings. Pigs fed from feeders with the wide adjustment had increased $(P<0.05)$ ADFI and decreased $(P<0.05) \mathrm{G}$ :F compared with pigs fed from feeders with the narrow adjustment. Feeders with the wider feeder gap setting had increased pan coverage $(P<0.001)$.

For diet form, the pigs fed poor-quality pellets unexpectedly tended to have increased $(P<0.10)$ ADG compared with pigs fed either of the other 2 diet form treatments. Pigs fed the meal or poor-quality pelleted diets had increased $(P<0.05)$ ADFI compared with pigs fed the screened pellets. The response to diet form on feed efficiency was identical to phase 1 , in which pigs fed the screened pellets had the best $(P<0.05)$ $\mathrm{G}: \mathrm{F}$, pigs fed the meal diet had the poorest G:F, and pigs fed poor-quality pellets had intermediate G:F. Feeders with screened pellets had lower $(P<0.05)$ pan coverage compared to feeders with unscreened pellets but higher $(P<0.05)$ coverage than feeders with meal diets.

The phase 3 poor-quality pellets contained $45 \%$ pellets and $55 \%$ fines whereas the screened pelleted diet was $90 \%$ pellets and $10 \%$ fines. There was no difference in ADG, ADFI, or G:F between pigs fed from feeders with the different adjustment settings during the final phase, although the numerical trends for ADFI and G:F were similar to previous phases. Although the magnitude of difference was lower, similar to other phases, feeders with the wider feeder gap setting had increased pan coverage $(P<0.001)$.

For diet form, pigs fed the meal diet had decreased $(P<0.05)$ ADG compared with pigs fed either of the pelleted diets, and pigs fed the high-quality pellets diet had decreased $(P<0.05)$ ADFI compared with pigs fed the meal or poor-quality pellets. Similar to the previous 2 periods, pigs fed the screened, high-quality pel-

Table 3. Effects of diet form and feeder adjustment on nursery pig growth performance, Exp. $1^{1}$

\begin{tabular}{|c|c|c|c|c|c|c|c|c|c|c|}
\hline & \multicolumn{2}{|c|}{ Minimum feeder gap opening } & \multirow[b]{2}{*}{ SEM } & \multicolumn{3}{|c|}{ Diet form } & \multirow[b]{2}{*}{ SEM } & \multicolumn{3}{|c|}{ Probability, $P<$} \\
\hline & $1.27 \mathrm{~cm}$ & $2.54 \mathrm{~cm}$ & & Meal & $\begin{array}{l}\text { Poor-quality } \\
\text { pellet }\end{array}$ & Pellet & & $\begin{array}{c}\text { Diet form } \times \text { feeder } \\
\text { adjustment }\end{array}$ & $\begin{array}{l}\text { Feeder } \\
\text { adjustment }\end{array}$ & $\begin{array}{l}\text { Diet } \\
\text { form }\end{array}$ \\
\hline \multicolumn{11}{|l|}{ d 0 to 21} \\
\hline ADG, g & 599 & 611 & 5.55 & $629^{\mathrm{a}}$ & $593^{\mathrm{b}}$ & $593^{\mathrm{b}}$ & 6.80 & 0.138 & 0.134 & 0.001 \\
\hline ADFI, $g$ & 875 & 897 & 11.35 & $938^{\mathrm{a}}$ & $875^{\mathrm{b}}$ & $845^{\mathrm{b}}$ & 13.90 & 0.300 & 0.177 & 0.001 \\
\hline $\mathrm{G}: \mathrm{F}$ & 0.685 & 0.682 & 0.006 & $0.672^{\mathrm{b}}$ & $0.678^{\mathrm{b}}$ & $0.702^{\mathrm{a}}$ & 0.007 & 0.967 & 0.727 & 0.010 \\
\hline \multicolumn{11}{|l|}{$\mathrm{BW}, \mathrm{kg}$} \\
\hline $\mathrm{d} 0$ & 11.9 & 11.9 & 0.13 & 11.9 & 11.9 & 11.9 & 0.16 & 0.999 & 0.981 & 0.998 \\
\hline d 21 & 24.2 & 24.7 & 0.21 & $25.1^{\mathrm{a}}$ & $24.3^{\mathrm{b}}$ & $24.3^{\mathrm{b}}$ & 0.26 & 0.533 & 0.412 & 0.077 \\
\hline Pan coverage on $\mathrm{d} 21, \%$ & 41.2 & 94.1 & 2.07 & 66.6 & 71.6 & 64.7 & 2.54 & .0770 & 0.001 & 0.162 \\
\hline
\end{tabular}

${ }^{\text {a,b} W i t h i n ~ a ~ r o w, ~ m e a n s ~ f o r ~ d i e t ~ f o r m ~ w i t h o u t ~ a ~ c o m m o n ~ s u p e r s c r i p t ~ s i g n i f i c a n t l y ~ d i f f e r ~}(P<0.05)$.

${ }^{1}$ A total of 210 nursery pigs (PIC $1,050 \times 327$ ) were used with 7 pigs per pen and 5 pens per treatment. For the main effect of feeder adjustment, there were 15 pens (replications) per treatment. For the main effect of diet form, there were 10 pens (replications) per treatment. 
Table 4. Effects of diet form and feeder adjustment on nursery pig growth performance, Exp. $2^{1}$

\begin{tabular}{|c|c|c|c|c|c|c|c|c|c|c|}
\hline & \multicolumn{2}{|c|}{ Minimum feeder gap opening } & \multirow[b]{2}{*}{ SEM } & \multicolumn{3}{|c|}{ Diet form } & \multirow[b]{2}{*}{ SEM } & \multicolumn{3}{|c|}{ Probability, $P<$} \\
\hline & $1.27 \mathrm{~cm}$ & $2.54 \mathrm{~cm}$ & & Meal & $\begin{array}{c}\text { Poor-quality } \\
\text { pellet }\end{array}$ & Pellet & & $\begin{array}{c}\text { Diet form } \times \text { feeder } \\
\text { adjustment }\end{array}$ & $\begin{array}{l}\mathrm{r} \text { Feeder } \\
\text { adjustment }\end{array}$ & $\begin{array}{l}\text { Diet } \\
\text { form }\end{array}$ \\
\hline \multicolumn{11}{|l|}{$\mathrm{d} 0$ to 28} \\
\hline ADG, $\mathrm{g}$ & 708 & 730 & 8.65 & $703^{\mathrm{a}}$ & $726^{\mathrm{b}}$ & $730^{\mathrm{b}}$ & 8.02 & 0.883 & 0.020 & 0.026 \\
\hline ADFI, $g$ & 1,098 & 1,139 & 18.55 & 1,116 & 1,134 & 1,102 & 16.24 & 0.889 & 0.025 & 0.252 \\
\hline G:F & 0.645 & 0.641 & 0.008 & $0.630^{\mathrm{b}}$ & $0.640^{\mathrm{b}}$ & $0.663^{\mathrm{a}}$ & 0.007 & 0.944 & 0.703 & 0.007 \\
\hline \multicolumn{11}{|l|}{$\mathrm{BW}, \mathrm{kg}$} \\
\hline $\mathrm{d} 0$ & 14.2 & 14.1 & 0.09 & 14.2 & 14.1 & 14.1 & 0.08 & 0.996 & 0.929 & 0.984 \\
\hline $\mathrm{d} 28$ & 34.0 & 34.6 & 0.16 & $33.8^{\mathrm{a}}$ & $34.4^{\mathrm{b}}$ & $34.6^{\mathrm{b}}$ & 0.15 & 0.867 & 0.024 & 0.048 \\
\hline Pan coverage on $\mathrm{d} 28, \%$ & 57.3 & 98.5 & 3.09 & 75.25 & 80.6 & 77.9 & 2.53 & 0.584 & 0.001 & 0.484 \\
\hline
\end{tabular}

a,b Within a row, means for diet form without a common superscript significantly differ $(P<0.05)$.

${ }^{1}$ A total of 1,005 nursery pigs (Fast $\times$ PIC sows $\times$ TR4 boars) were used with 26 to 28 pigs per pen and 6 pens per treatment. For the main effect of feeder adjustment, there were 18 pens (replications) per treatment. For the main effect of diet form, there were 12 pens (replications) per treatment.

lets had the best $(P<0.05) \mathrm{G}: \mathrm{F}$, pigs fed the meal diet had the poorest $\mathrm{G}: \mathrm{F}$, and pigs fed poor-quality pellets had intermediate G:F. For pan coverage score, feeders with the unscreened pellets had higher $(P=0.02)$ pan coverage compared with feeders with meal diets while feeders with screened pellets were intermediate.
Overall (d 0 to 69), feeder adjustment had no effect on ADG. Responses from phases 1 and 2 carried over into the overall data, resulting in decreased $(P<0.05)$ ADFI and improved $(P<0.05) \mathrm{G}: \mathrm{F}$ in pigs fed from the narrow-adjusted feeders. Pigs fed meal diets had decreased $(P<0.05)$ ADG compared with pigs fed the

Table 5. Effects of diet form and feeder adjustment on finishing pig growth performance, Exp. $3^{1}$

\begin{tabular}{|c|c|c|c|c|c|c|c|c|c|c|}
\hline & \multicolumn{2}{|c|}{ Minimum feeder gap opening } & \multirow[b]{2}{*}{ SEM } & \multicolumn{3}{|c|}{ Diet form } & \multirow[b]{2}{*}{ SEM } & \multicolumn{3}{|c|}{ Probability, $P<$} \\
\hline & $1.27 \mathrm{~cm}$ & $2.54 \mathrm{~cm}$ & & Meal & $\begin{array}{c}\text { Poor-quality } \\
\text { pellet }\end{array}$ & Pellet & & $\begin{array}{c}\text { Diet form } \times \text { feeder } \\
\text { adjustment }\end{array}$ & $\begin{array}{c}\text { Feeder } \\
\text { adjustment }\end{array}$ & $\begin{array}{l}\text { Diet } \\
\text { form }\end{array}$ \\
\hline \multicolumn{11}{|l|}{ d 0 to 22} \\
\hline $\mathrm{ADG}, \mathrm{kg}$ & 0.97 & 0.98 & 0.017 & 0.97 & 0.95 & 0.99 & 0.021 & 0.880 & 0.611 & 0.319 \\
\hline ADFI, kg & 2.19 & 2.30 & 0.040 & $2.35^{\mathrm{a}}$ & $2.21^{\mathrm{b}}$ & $2.18^{\mathrm{b}}$ & 0.049 & 0.662 & 0.069 & 0.039 \\
\hline $\mathrm{G}: \mathrm{F}$ & 0.442 & 0.427 & 0.004 & $0.415^{\mathrm{a}}$ & $0.431^{b}$ & $0.457^{\mathrm{c}}$ & 0.005 & 0.765 & 0.016 & 0.001 \\
\hline \multicolumn{11}{|l|}{ d 22 to 48} \\
\hline $\mathrm{ADG}, \mathrm{kg}$ & 1.01 & 1.03 & 0.012 & $1.00^{\mathrm{a}}$ & $1.05^{\mathrm{b}}$ & $1.01^{\mathrm{a}}$ & 0.015 & 0.525 & 0.280 & 0.056 \\
\hline ADFI, kg & 2.60 & 2.76 & 0.044 & $2.79^{\mathrm{a}}$ & $2.74^{\mathrm{a}}$ & $2.51^{\mathrm{b}}$ & 0.054 & 0.490 & 0.017 & 0.002 \\
\hline $\mathrm{G}: \mathrm{F}$ & 0.391 & 0.376 & 0.004 & $0.360^{\mathrm{a}}$ & $0.385^{b}$ & $0.405^{\mathrm{c}}$ & 0.005 & 0.130 & 0.030 & 0.001 \\
\hline \multicolumn{11}{|l|}{ d 48 to 69} \\
\hline $\mathrm{ADG}, \mathrm{kg}$ & 0.97 & 0.97 & 0.018 & $0.92^{\mathrm{a}}$ & $0.99^{\mathrm{b}}$ & $1.00^{\mathrm{b}}$ & 0.022 & 0.742 & 0.934 & 0.041 \\
\hline ADFI, kg & 3.23 & 3.35 & 0.063 & $3.41^{\mathrm{a}}$ & $3.36^{\mathrm{a}}$ & $3.10^{\mathrm{b}}$ & 0.077 & 0.340 & 0.173 & 0.016 \\
\hline $\mathrm{G}: \mathrm{F}$ & 0.301 & 0.292 & 0.005 & $0.273^{\mathrm{a}}$ & $0.294^{b}$ & $0.323^{\mathrm{c}}$ & 0.006 & 0.756 & 0.219 & 0.001 \\
\hline \multicolumn{11}{|l|}{ d 0 to 69} \\
\hline $\mathrm{ADG}, \mathrm{kg}$ & 0.98 & 1.00 & 0.011 & $0.97^{\mathrm{a}}$ & $0.99^{\mathrm{ab}}$ & $1.00^{\mathrm{b}}$ & 0.014 & 0.722 & 0.463 & 0.162 \\
\hline ADFI, kg & 2.66 & 2.79 & 0.042 & $2.84^{\mathrm{a}}$ & $2.75^{\mathrm{a}}$ & $2.58^{\mathrm{b}}$ & 0.051 & 0.515 & 0.033 & 0.004 \\
\hline $\mathrm{G}: \mathrm{F}$ & 0.371 & 0.359 & 0.003 & $0.343^{\mathrm{a}}$ & $0.363^{b}$ & $0.390^{\mathrm{c}}$ & 0.004 & 0.450 & 0.020 & 0.001 \\
\hline \multicolumn{11}{|l|}{$\mathrm{BW}, \mathrm{kg}$} \\
\hline $\mathrm{d} 0$ & 56.8 & 56.8 & 0.69 & 56.8 & 56.8 & 56.8 & 0.84 & 0.999 & 0.994 & 0.999 \\
\hline d 22 & 78.3 & 78.4 & 0.87 & 78.3 & 78.1 & 78.7 & 1.07 & 0.965 & 0.932 & 0.914 \\
\hline d 48 & 104.8 & 105.4 & 1.07 & 104.3 & 105.7 & 105.4 & 1.32 & 0.893 & 0.735 & 0.736 \\
\hline d 69 & 125.4 & 125.8 & 1.22 & 123.6 & 126.8 & 126.4 & 1.50 & 0.753 & 0.845 & 0.289 \\
\hline \multicolumn{11}{|c|}{ Pan coverage, $\%$} \\
\hline $\mathrm{d} 22$ & 41.3 & 88.2 & 1.24 & $56.8^{\mathrm{c}}$ & $72.5^{\mathrm{a}}$ & $65.0^{\mathrm{b}}$ & 1.52 & 0.060 & 0.001 & 0.001 \\
\hline $\mathrm{d} 48$ & 69.5 & 93.5 & 1.26 & $76.4^{\mathrm{c}}$ & $87.8^{\mathrm{a}}$ & $80.5^{\mathrm{b}}$ & 1.03 & 0.188 & 0.001 & 0.001 \\
\hline d 69 & 91.4 & 96.7 & 0.87 & $92.2^{\mathrm{b}}$ & $95.8^{\mathrm{a}}$ & $94.3^{\mathrm{ab}}$ & 1.06 & 0.640 & 0.001 & 0.066 \\
\hline
\end{tabular}

${ }^{\mathrm{a}-\mathrm{c}}$ Within a row, means for diet form without a common superscript significantly differ $(P<0.05)$.

${ }^{1}$ A total of 246 finishing pigs (PIC $327 \times 1,050$ ) were used. There were 5 pens per treatment with 7 pigs and 1 replicate with 6 pigs per pen. For the main effect of feeder adjustment, there were 15 pens per treatment with 7 pigs and 3 replicates with 6 pigs per pen. For the main effect of diet form, there were 10 pens per treatment with 7 pigs and 2 replicates with 6 pigs per pen. 
screened pelleted diets, and pigs fed poor-quality pellets had intermediate ADG. Feeding screened pellets resulted in decreased $(P<0.05)$ ADFI compared with pigs fed poor-quality pellets or meal diets. Consistent with all 3 phases, pigs fed screened pellets had improved $(P<0.05)$ G:F compared with pigs fed the meal diet, and those fed poor-quality pellets had intermediate G:F.

\section{DISCUSSION}

Contrary to our expectations, we observed no feeder adjustment $\times$ diet form interactions in any of the experiments. We expected that a narrow feeder adjustment would be more beneficial for feeders with poor-quality pellets by providing better management of the fines. As evidenced by the photographs used to determine feeder pan coverage, feeders containing poor-quality pellets had a large buildup of fines in the edges of the pans. Despite our hypothesis, we found that the responses to feeder adjustment and diet form were independent. Other studies have observed that the response to pelleting varies among trials. Hedemann et al. (2005) found that no differences were observed in ADG or ADFI when feeding meal or pelleted diets to growing pigs. Conversely, Wondra et al. (1995) reported that feeding pelleted diets resulted in a 4 to $6 \%$ improvement in ADG compared with feeding meal. Myers et al. (2013) also observed discrepancies in growth performance response to diet form and attributed the differences to pellet quality. The authors concluded that feeding high-quality pellets improved growth performance compared with meal, but when pellet quality was poor, pelleting conferred no benefits in feed efficiency.

Despite variation in ADG and ADFI, our experiments agree that the greatest improvements in feed efficiency were observed from pigs fed screened pellets with minimal fines. Stark et al. (1993) found that feeding screened pellets to nursery pigs provided an $11 \%$ improvement in feed efficiency compared with feeding meal, whereas feeding pellets with $25 \%$ fines provided an $8 \%$ improvement. We observed that feeding screened pellets improved G:F by approximately 5\% in Exp. 1 and 2. For Exp. 3, pigs fed the meal diet had the poorest G:F, pigs fed screened pellets had the best $\mathrm{G}: \mathrm{F}$, and pigs fed poor-quality pellets had intermediate $\mathrm{G}: F$. Feeding the poor-quality pelleted diet provided approximately $6 \%$ improvement in G:F compared with feeding the meal diet. Wondra et al. (1995) and De Jong et al. (2013) reported similar improvements of 7 and $6 \%$, respectively, when finishing pigs were fed pelleted diets compared with meal diets. In Exp. 3 , however, finishing pigs fed screened pellets had a much greater improvement (14\%) in G:F compared with pigs fed meal.

The poor-quality pelleted diet contained approximately $50 \%$ pellets and $50 \%$ fines, but when the photographs of feeders with poor-quality pellets were evaluated, fines in the pan appeared to be much greater than $50 \%$. We believe that pigs sorted through the feed with a preference for the pelleted portion rather than the fines, leading to the visual increase in fines in the feeder relative to pellets. This may have led to increased wastage of fines, contributing to poorer feed efficiency compared with feeding screened pellets with minimal fines. Furthermore, data from Jensen and Becker (1965) supports the theory that the improvement in feed efficiency from pelleting is highly related to providing the diet in a pelleted physical form and not necessarily from processes occurring during pellet manufacturing. In a series of 3 experiments, the authors reported that pigs fed diets in pelleted form averaged an $8 \%$ improvement in G:F compared with pigs fed diets that were pelleted, reground, and then fed in meal form. Data from Ball et al. (2015) further supports the hypothesis that the greatest improvement in feed efficiency from pelleting is from reduced wastage. These researchers found improvements in energy digestibility in pigs fed pelleted diets, but the effect was small and accounted for only a small portion of the G:F improvement. The combination of data confirms previous research from Stark et al. (1993) that feeding pelleted diets improves feed efficiency, but the magnitude of improvement was greatest when the percentage of fines in the diet was minimized. Although the magnitude of response may vary, our 3 experiments agree that the percentage of fines in the diets must be minimized to obtain maximum benefits to feed efficiency from pelleting.

The composition of fines can also differ from the composition of intact pellets, especially if fat is sprayed on the pellets at the die (DeJong et al., 2015). Because of the method by which diets were manufactured and fines were generated, this phenomenon would not be applicable in this study. Fat was not sprayed on at the die in any of the experiments. In Exp. 1, some fines were generated through the normal deterioration of pellets; however, in Exp. 2 and 3, pellets were ground to create fines. Thus, fines and pellets would have the same composition.

Smith et al. (2004) reported that during a 42-d nursery experiment, feeding pigs from a wide feeder adjustment resulted in increased BW gain at the conclusion of the trial, but differences in ADG occurred only in the last $21 \mathrm{~d}$ of their trial. The varying response between the current experiments may be related to experiment duration or differences in university (Exp. 1) 
vs. field (Exp. 2) research conditions. The feeders in the university setting allowed for approximately 2.33 pigs per feeder hole, whereas feeders in the commercial setting allowed for 5 pigs per feeder hole. In addition, the length of the feeder pans allowed for 5.81 and $3.05 \mathrm{~cm}$ of eating space per pig in the university and commercial settings, respectively. Therefore, there was more competition for eating space in the commercial pens. This increase in competition may have been mitigated by the increased feeder pan coverage from the wide-adjusted feeders. Feeding pigs from a wide feeder adjustment most likely made feed more accessible and allowed pigs to spend less time at the feeder, thus, contributing to the increased ADG and ADFI observed in the commercial setting. Both experiments agree that feeder adjustment did not significantly influence feed efficiency. This is in agreement with Smith et al. (2004), who found no differences in G:F when nursery pigs were fed from feeders with pan coverage from 6 to $93 \%$. The combined results suggest that feeding nursery pigs from a wide feeder gap may provide benefits in ADG and ADFI with no negative effects on feed efficiency. These results were unexpected because the feeder pan was almost completely covered with the wide feeder adjustment and feed wastage was expected. We recognize that different feeder designs may influence this response; however, with the feeders used in the current experiment and by Smith et al. (2004), excessive feed in the pan did not appear to result in additional feed wastage.

Data from the present study of finishing pigs showed that feeder adjustment did not influence gain. Conversely, Myers et al. (2012) reported that from 41 to $68 \mathrm{~kg} \mathrm{BW}$, providing $28 \%$ pan coverage limited access to feed and decreased ADG compared with pigs fed from feeders with 58 or $75 \%$ pan coverage. Similarly, Duttlinger et al. (2009) found that $24 \%$ pan coverage restricted feed intake and limited the growth of finishing pigs. The lack of ADG response in the current trial may be owing to relatively high feeder pan coverage on the narrow feeder adjustment, which averaged a minimum of $41 \%$ during phase 1 . At the same feeder setting, feeder pan coverage scores increased over time for the narrow feeder setting. Increasing pan coverage further with the wide adjustment appears to have increased feed wastage and, thus, resulted in poor feed efficiency during phase 1,2 , and for the overall trial. Thus, monitoring the feeder gap opening to properly manage feeder pan coverage appears to be able to help minimize feed wastage and improve feed efficiency in finishing pigs. This result is in agreement with Myers et al. (2012), who suggested that a decreased feeder gap opening should be used to feed heavier pigs.
In summary, in this study and with the type of feeders used, no feeder adjustment $\times$ diet form interactions were detected. Results from Exp. 1 and 2 suggest that feeding nursery pigs from a wide feeder gap may provide benefits in ADG and ADFI when feeder space allowance is reduced; however, feeder adjustment appeared to have little influence on feed wastage for nursery pigs. In contrast, reducing feeder gap width led to less feeder pan coverage for finishing pigs and allowed for decreased feed wastage and improved feed efficiency, with no effect on ADG. In all experiments, feeding pelleted diets improved G:F, but the improvement was greatest when the percentage of fines was minimized.

\section{LITERATURE CITED}

ASAE. 1987. Wafers, pellets, and crumbles- definitions and methods for determining density, durability, and moisture content. ASAE Standard S269.3. In: Agricultural engineers yearbook of standards. Am. Soc. Agric. Biol. Eng., St. Joseph, MI. p. 318.

Baird, D. M. 1973. Influence of pelleting swine diets on metabolizable energy, growth and carcass characteristics. J. Anim. Sci. 36:516-521.

Ball, M. E. E., E. Magowan, K. J. McCracken, V. E. Beattie, R. Bradford, A. Thompson, and F. J. Gordon. 2015. An investigation into the effects of dietary particle size and pelleting of diets for finishing pigs. Livest. Sci. 173:48-54.

De Jong, J. A., J. M. DeRouchey, M. D. Tokach, R. D. Goodband, S. S. Dritz, J. L. Nelssen, and C. Hastad. 2013. Effects of corn particle size, complete diet grinding, and diet form on pig growth performance, caloric efficiency, and carcass characteristics. J. Anim. Sci. 91(Suppl. 2):216 (Abstr.)

De Jong, J. A., J. M. DeRouchey, M. D. Tokach, R. D. Goodband, J. C. Woodworth, C. K. Jones, C. R. Stark, L. McKinney, G. Smith, and J. A. Erceg. 2015. Formation of fines during the pelleted feed manufacturing process and the resulting difference in nutrient composition of fines and pellets. J. Anim. Sci. 93(Suppl. 2):62 (Abstr.)

Duttlinger, A. W., S. S. Dritz, M. D. Tokach, J. M. DeRouchey, J. L. Nelssen, and R. D. Goodband. 2009. Effects of feeder adjustment on growth performance of finishing pigs. J. Anim. Sci. 87(Suppl. 3):184 (Abstr.)

Hedemann, M. S., L. L. Mikkelsen, P. J. Naughton, and B. B. Jensen. 2005. Effect of feed particle size and feed processing on morphological characteristics in the small and large intestine of pigs and on adhesion of Salmonella enterica serovar Typhimurium DT12 in the ileum in vitro. J. Anim. Sci. $83: 1554-1562$.

Jensen, A. H., and D. E. Becker. 1965. Effect of pelleting diets and dietary components on the performance of young pigs. J. Anim. Sci. 24:392-397.

Myers, A. J., R. D. Goodband, M. D. Tokach, S. S. Dritz, J. M. DeRouchey, and J. L. Nelssen. 2012. The effects of feeder adjustment and trough space on growth performance of finishing pigs. J. Anim. Sci. 90:4576-4582.

Myers, A. J., R. D. Goodband, M. D. Tokach, S. S. Dritz, J. M. DeRouchey, and J. L. Nelssen. 2013. The effects of diet form and feeder design on growth performance of finishing pigs. J. Anim. Sci. 91:3420-3428. 
NRC. 2012. Nutrient requirements of swine. 11th rev. ed. Natl. Acad. Press, Washington, DC.

Smith, L. F., A. D. Beaulieu, J. F. Patience, H. W. Gonyou, and R. D. Boyd. 2004. The impact of feeder adjustment and group size-floor space allowance on the performance of nursery pigs. J. Swine Health Prod. 12:111-118.
Stark, C. R., K. C. Behnke, J. D. Hancock, and R. H. Hines. 1993. Pellet quality affects growth performance of nursery and finishing pigs. In: Proc. Swine Day, Manhattan, KS. Kansas State University, Manhattan. p. 71-74.

Wondra, K. J., J. D. Hancock, K. C. Behnke, R. H. Hines, and C. R. Stark. 1995. Effects of particle size and pelleting on growth performance, nutrient digestibility, and stomach morphology in finishing pigs. J. Anim. Sci. 73:757-763. 
Reproduced with permission of the copyright owner. Further reproduction prohibited without permission. 